January/February 2001

\section{ISSUE FOCUS:}

Industrial System

Maintenance

\section{IN THIS ISSUE}

Compressed Air System Upgrade Generates Significant Energy

Savings at Steel Mill ............. 1

Guest Column: Computerized

Maintenance Management Systems-

Justifying the Cost . . . . . . . . . 3

OIT Helps SMUD Provide a Full

Range of Services ............ 4

Performance Optimization Tips-

The Rules of the Game . . . . . . . . 5

Ask the Clearinghouse .......... 6

New Steam System Scoping Tool

Provides Assessment Information . . . . 7

Letters to the Editor ........... 7

Energy Matters Extra Highlights $\ldots \ldots 7$

Coming Events $\ldots \ldots \ldots \ldots \ldots \ldots$

New Steam System Scoping Tool, see page 7 .

\section{INSERT:}

Timely tips for reducing
natural gas bills

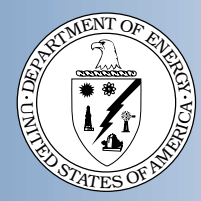

\section{OFFICE OF INDUSTRIAL} TECHNOLOGIES •

U.S. DEPARTMENT OF ENERGY

Www.oit.doe.gov

www.oit.doe.gov/bestpratices

\section{Compressed Air System Upgrade Generates Significant Energy Savings at Steel Mill}

In 1996, U. S. Steel completed a project in which the main compressed air system at its Edgar Thomson Plant in Braddock, Pennsylvania, was overhauled. A key goal was reducing maintenance on its air compressors. Not only was this goal met, but the plant also

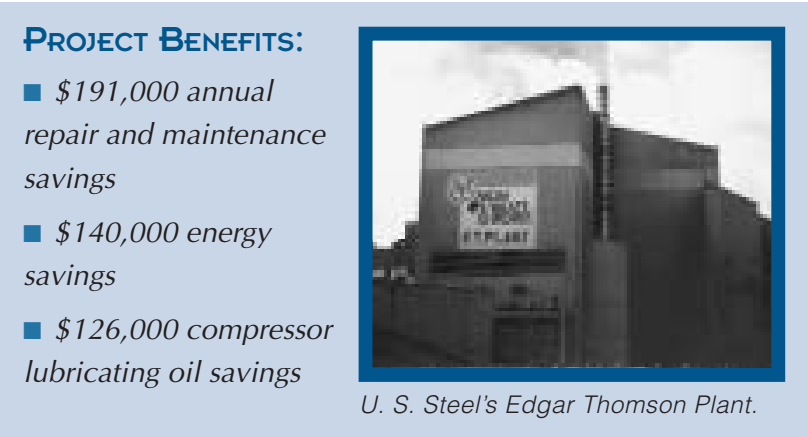
reduced energy use, and reaped annual savings of $\$ 457,000$.

U. S. Steel is part of USX Corporation, which is headquartered in Pittsburgh, Pennsylvania. The U. S. Steel subsidiary manufactures a variety of steel mill products, coke, and taconite pellets. Its Edgar Thomson Plant converts iron ore into steel and makes steel slabs.

The main compressed air system is vital to the plant's production process because it serves the Basic Oxygen Plant, two blast furnaces, and the powerhouse. The main uses of compressed air are for the pneumatic actuators and pistons that actuate large cylinders. Prior to the system overhaul, the plant's compressed air system was served by six aging 400-hp air- and oilcooled, rotary screw compressors that were spread out over the plant. These compressors leaked oil, broke down frequently, and could no longer provide air at the pressure level for which they were rated.

Plant engineers reviewed the compressed air system and realized that simply replacing the old compressors would not solve the system's problems. Based on experience, the engineers knew that a systemlevel strategy was necessary to address the problem effectively. First, the engineers examined the six compressors, installed in the (continued on page 2)

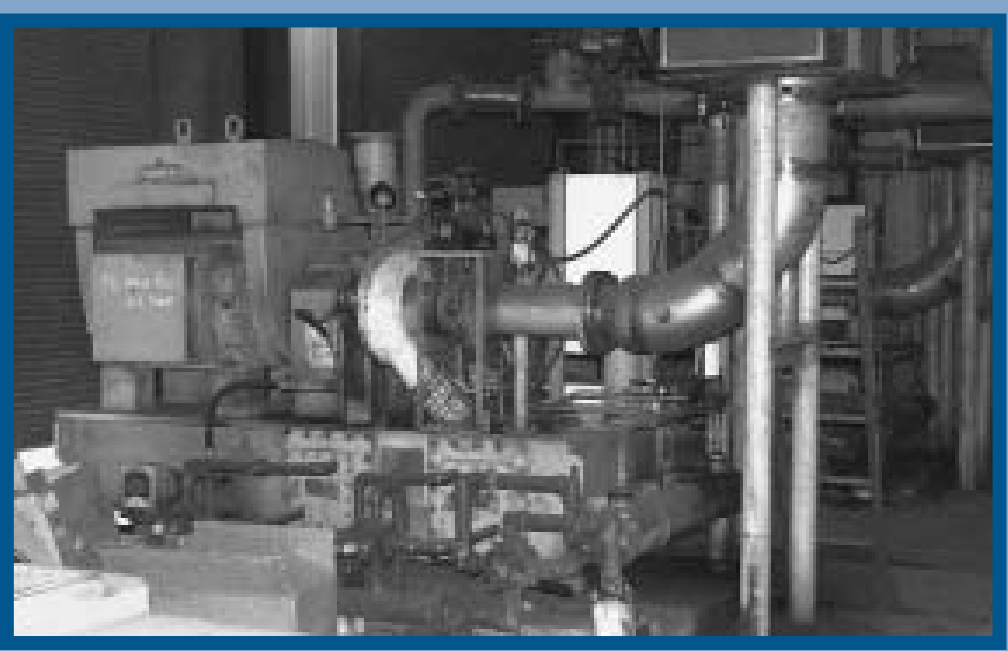

U. S. Steel replaced old, unreliable rotary screw compressors with 600-hp centrifugal compressors, shown here, at its Edgar Thomson Plant in Braddock, Pennsylvania. 


\section{ENERgy MATTERS}

is published bimonthly by the U.S. Department of Energy's

(DOE) Office of Industrial Technologies.

Information contained in the newsletter can be reproduced without permission provided due acknowledgement is given (the U.S. Department of Energy's Energy Matters newsletter) and a copy of the publication is supplied to the editor.

EDITORIAL BOARD

Rob Boteler, representing National Electrical Manufacturers Association

Lynda Butek, representing Electrical Apparatus Service Association

Don Casada, OIT BestPractices Program

Keith Davidson, Onsite Sycom Energy

Bob Gemmer, U.S. DOE, Process Heating

Glenn Hahn, Spirax Sarco

Fred Hart, U.S. DOE, Steam

Chris Hunter, Johnson \& Johnson

Aimee McKane, OIT BestPractices Program

Rick Payton, Rockwell

Automation/Reliance Electric

Bill Stafford, Technical

Association of the Pulp and Paper Industry

Chuck Whelan, DuPont

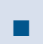

COMMENTS?

Contact:

Michelle Mallory, Energy Matters Editor, at (303) 275-3627, or e-mail michelle_sosa-mallory@nrel.gov

1617 Cole Blvd., MS 1713

Golden, CO 80401

For address/subscription changes, please contact the editor.
Compressed Air System Upgrade continued from page 1

early 1980s, and determined that they were so worn that repairing them was not cost-effective. By 1996, they operated so poorly that they could not produce the airflow and pressures they were rated for, forcing the plant to borrow compressed air from other systems.

Moreover, the oil leakage caused many problems. It imposed excessive maintenance and lubricant costs because the oil had to be replaced frequently. The oil was also carrying over into the end-use equipment, leading to unreliable product quality. Oil had contaminated the air dryers and filters to the point that it severely obstructed the airflow, which led to a severe pressure drop across the system. Hence, although the plant operated the compressors at discharge pressures of 90 pounds per square inch gauged (psig) or more, the end-use applications were barely receiving air at their minimum required pressure of $60 \mathrm{psig}$.

Finally, the plant identified some large leaks and inappropriate uses of compressed air that were contributing to excess air demand and were wasting energy.

The plant took the rotary screw compressors offline and installed two 600-hp centrifugal compressors in a central location that required minimal engineering and equipment to connect the compressors. A few of the rotary screw compressors were kept for back-up use and for use during extreme hot or cold weather. Because of their poor condition, these rotary screw compressors are seldom used due to the risk of introducing oil and dirt into the system.

Next, the plant installed two new dryers, one for each of the new compressors and new filters in the air/lubricant separators. At the same time, the plant performed a leak detection/repair campaign and eliminated some inappropriate uses, such as blow-off and spot cooling applications.

Once all of the equipment was in place and the leak repair was complete, the plant began operating the new compressors at a discharge pressure of 90 psig. The plant engineers found that the end-use applications were receiving air at 80 psig. Because the end-use applications could operate at $60 \mathrm{psig}$, the engineers began to gradually lower the compressor discharge pressure to $70 \mathrm{psig}$.
With the newly configured system, the plant operates more effectively with less total horsepower. Also, the reduction in lubricant carryover and associated compressor downtime has improved the reliability of the plant and eliminated its dependence on other systems.

George Fignar, senior engineer, said, "The reduced maintenance needs of the new compressors released our staff from the burden that the maintenance on the old compressors represented. This allowed us to deploy them in other areas of the plant and increased their capacity to maintain other machines more effectively."

U. S. Steel spent $\$ 521,000$ to implement this project, but it is saving $\$ 457,000$ per year, leading to a simple payback of 13.5 months. Of the total savings, $\$ 140,000$ is energy savings, $\$ 126,000$ is compressor lubricating oil savings, and $\$ 191,000$ is annual repair and maintenance savings.

The energy savings represents about $18 \%$ of the plant's annual compressed air energy costs. Much of the energy savings occurred because the compressors' discharge pressure was lowered by 20 psig.

By using a systems approach towards equipment replacement and adjusting the pressure to the lowest level that served the plant's requirements, the Edgar Thomson Plant increased the efficiency of its compressed air system. This has reduced energy use and saved nearly half a million dollars per year.

Read the full case study on U. S. Steel's efforts to improve its compressed air system at www.oit.doe.gov/bestpractices/ explore_library. To read a similar article about how a compressed air system upgrade reduced maintenance, downtime, and energy costs at the Thomaston Textile Mill, log on to Energy Matters Extra at www.oit.doe.gov/bestpractices/explore library/emextra.

Recently, U. S. Steel partnered with OIT to host the Pittsburgh Regional Technology Showcase. This public event highlighted the significant savings the Edgar Thomson Plant has achieved from energy efficiency and other measures to improve productivity. Your plant could be a Showcase Demonstration site, too. Learn how by visiting www.oit.doe.gov/bestpractices/ explore_library/showcase.shtml. 


\section{Guest Column}

Computerized Maintenance

Management Systems-

Justifying the Cost

By W.L. (Chris) Christy, Jr., P.E.,

The LawGibb Group, Atlanta, GA

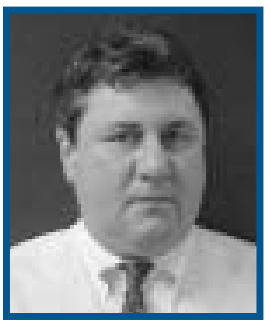

Computerized maintenance management systems (CMMS) are effective tools in managing operations and maintenance costs, but the initial implementation costs are typically high. The best way to justify these costs is to quantify the benefits.

In 20-plus years of automating facility management functions, I have worked with hundreds of maintenance managers and plant engineers to develop programs, secure funding, and implement and manage day-to-day operations. In my experience, the biggest obstacle is convincing management to fund the project. The task of quantifying the benefits on paper-and in a language that a controller or CFO easily understands-is daunting, even for the best technical managers.

This task can be a little less frustrating by following a few simple guidelines and examples. First, identify all of the benefits, both tangible and intangible, but stay focused on the tangible. That's where the savings are. An example of an intangible benefit is faster access to information. This expedites and improves the accuracy of decisions, but is very difficult to quantify. However, the tangible benefits are easier to quantify. We'll discuss these below using examples of how to generate reasonable figures that make sense to financial people in the company.

\section{Demonstrate the Tangible Benefits}

Let's look at the big picture areas where a sound CMMS program can result in operational cost savings. Numbers like the ones used in these examples are generally available somewhere in the organization, but typically not in one place. Be prepared to do some work gathering them. Keep in mind, however, this is what you'll need to show senior management before convincing them to foot the bill for a CMMS.

\section{Downtime Reductions}

In process control, materials handling, and manufacturing environments, downtime is often the single biggest issue that impacts the bottom line. Within the production group, the amount, frequency, and cost of downtime is typically a wellknown figure. Maintenance managers and plant engineers should also be familiar with these numbers.

Good preventive maintenance can often reduce the amount of downtime. If, for example, a round-the-clock plant experiences 1 hour of unscheduled downtime per week, and the cost of downtime is $\$ 5,000$ per hour, that is $\$ 5,000$ per week of lost production. If improved maintenance can reduce downtime to $15 \mathrm{~min}$ utes, the annual savings would be $\$ 195,000$ based on this simple calculation:

Savings $=(1 \mathrm{hr}-.25 \mathrm{hr}) \times \$ 5,000 \mathrm{loss} / \mathrm{hr}$

$$
=0.75 \mathrm{hr} \times \$ 5,000
$$$$
=\$ 3,750 / \mathrm{wk}
$$

$\$ 3,750 / \mathrm{wk} \times 52 \mathrm{wks} / \mathrm{yr}$

$$
=\$ 195,000 / \mathrm{yr}
$$

A well-implemented CMMS helps ensure scheduled and timely maintenance. It will alert managers to problems that often go unnoticed or equipment that continues to fail and is repaired repeatedly.

\section{Reduced Product Loss (Improved QC)}

Quality is often compromised when equipment fails to perform as intended, and product loss can be directly or indirectly attributed to equipment failure. As with reduced downtime, a CMMS applied here would ensure timely and scheduled maintenance and could reduce losses.

In this example, assume a situation where equipment problems are causing $\$ 5,000$ per week of product loss or damage. If a CMMS could reduce this to $\$ 1,000$ per week, the annual savings would be as follows:

$$
\begin{aligned}
& \text { Savings }=(\$ 5,000 \text { loss } / \mathrm{wk}-\$ 1,000 \\
& \quad \text { loss } / \mathrm{wk}) \\
& =\$ 4,000 \times 52 \text { weeks } \\
& =\$ 208,000 / \mathrm{yr}
\end{aligned}
$$

\section{Energy Reductions}

It's important to consider the potential energy savings related to plant mainte- nance because these savings can add up quickly. For example, a distribution facility of approximately 750,000 square feet has a medium-size conveying system. The system uses 200 single-phase drive motors totaling $4000 \mathrm{hp}$ rated at $80 \%$ efficiency. Let's assume less than ideal maintenance practices have caused a loss of $3 \%$. Regaining the $3 \%$ through improved maintenance will result in these savings:

4000 hp x 2544 Btu/hp $\div 3413$ Btu/kW $=2981 \mathrm{~kW}$

Present power requirement $=2981 \mathrm{~kW} \div$ $77 \%=3871 \mathrm{~kW}$

Improved power requirement $=2981 \mathrm{~kW} \div$ $80 \%=3726 \mathrm{~kW}$

Savings $=(3871 \mathrm{~kW}-3726 \mathrm{~kW}) \mathrm{x}$ $2000 \mathrm{hrs} / \mathrm{yr} \times \$ 0.05 / \mathrm{kWh}$ $=\$ 14,500 / \mathrm{yr}$

The CMMS generates scheduled work orders that contain, at a minimum, the manufacturer's recommended procedures to keep the equipment in top operating condition-or peak efficiency.

\section{Optimized Staffing and Improved} Productivity

A key consideration for managers is optimizing staff to meet workflow requirements. Without a CMMS, calculating labor costs and potential savings is time consuming. However, a fully implemented CMMS will contain information, such as base rates, loaded rates, and company fringe rates, to help streamline this analysiswhich otherwise may not be done.

In addition to helping managers optimize staff numbers, a CMMS can help improve the staff's productivity. For example, a plant's maintenance staff of 50 has an average labor rate of $\$ 30$ per hour. If implementing the system increases each employee's productivity by 5 minutes per hour, the annual savings would be $\$ 260,000$ as follows:

(continued on page 6)

\section{Estimate the Cost to Implement a CMMS}

Generally, implementation costs for a CMMS are driven by the cost of software and the cost of data collection. Likewise, the cost of data collection depends on the number of equipment items to be inventoried and the number of system features that will be utilized day-to-day. As the level of sophistication increases, so does the cost of implementation. Plan your implementation budget using an estimate of \$25 to \$50 per equipment item, plus the cost of the software. 


\section{OIT Helps SMUD Provide a Full Range of Services}

California's Sacramento Municipal Utility District (SMUD) offers its customers a variety of assistance and tools to help them improve the efficiency of their motor, pump, and other process systems. To this end, SMUD has taken advantage of OIT resources to help educate customers and SMUD staff.

To educate customers and raise awareness of motor system efficiency opportunities, SMUD, in conjunction with OIT, has offered the following OIT workshops:

- Motor Systems Management, with MotorMaster+ software training

- Compressed Air System Efficiency

- Adjustable Speed Drives, with ASDMaster software training

- Pumping System Assessment Tool (PSAT) training

- Advanced Management of Compressed Air Systems

"We hosted a PSAT seminar for the benefit of our customers, but we benefited as well... It has been very valuable having OIT resources to draw from..." said Doug Norwood of SMUD.

SMUD utilizes OIT resources to promote and support a systems approach to motor and compressed air system efficiency. Harlan Coomes, senior demand-side specialist for SMUD's Energy Services Department, said recently that the workshops "led directly to project implementation and added significant value to our program."

The utility district has found that it is in the customer's best interest to take a whole-systems approach. Hence, it provides a continuum of services-financial incentives, energy assessments, motor or pump testing, compressed air system audits, diagnostic inspections, and education or analysis tools. These services can be accessed through SMUD's Energy Services Department.

One of SMUD's programs-the Commercial and Industrial (C/I) Retrofit Program-assists customers in learning about, purchasing, and installing energy-efficient technologies and measures. Following are summaries of some of the customer support services SMUD offers through this program.

\section{Motor System Efficiency Initiative}

The SMUD Motor System Efficiency Initiative provides efficiency information via motor testing and reports, MotorMaster+ software, OIT workshops, and technical field staff. These tools, combined with incentives and financing to help initiate projects, form the core of the initiative's activities. The benefits are optimized motor life, reduced maintenance costs, minimized unscheduled downtime, improved energy efficiency, and improved motor quality assurance.

Recent diagnostic testing at a GeorgiaPacific Resin plant uncovered motor and wiring defects and prevented a \$60,000 product loss. Similarly, Citizen Utilities Water District saved $\$ 12,000$ in motor rewind costs because of SMUD's diagnostic testing.

\section{Diagnostic Services}

Diagnostic services offered by SMUD's Retrofit Program include:

- Pump testing

- Ultrasonic leak detection

- Infrared imaging

- Equipment calibration and repair

\section{Pump Testing}

SMUD staff conducts about 400 pump tests per year, free of charge, on pump systems with a wide range of discharge capacities. Pump testing characterizes the

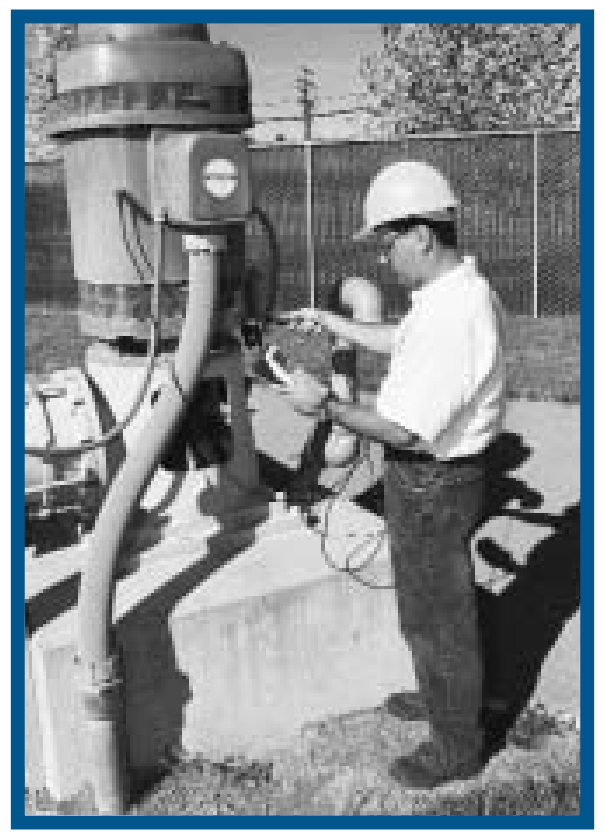

SMUD technical staff tests customers' motors as part of its Motor System Efficiency Initiative. operational efficiency and capacity of pumps and wells by identifying standing water levels, drawdown levels, pumping capacity, yields, and kilowatt input to motors.

Pump testing results at Sacramento's Sutter General Hospital have convinced management to replace its water pump system, which should net annual cost savings of $\$ 6,505$.

\section{Energy Auditing and Tracking}

SMUD energy specialists conduct on-site inspections, free of charge, and produce tailored reports identifying improvement strategies, estimated costs, and projected savings. These services have also helped customers improve energy management and maintenance practices.

In 1999, SMUD staff attended the Fundamentals of Compressed Air Systems training offered through the Compressed Air Challenge Program and sponsored by OIT and the Consortium for Energy Efficiency (CEE). Staff applied this knowledge during assessments at the 7-UP and Pepsi bottling plants in Sacramento. Two projects were identified to help improve efficiency and productivity. Together, the projects saved $351.6 \mathrm{~kW} ; 1,093,565 \mathrm{kWh}$; and $\$ 106,415$.

\section{Project Completion Incentives}

Customers can also access financial incentives to help improve their energy efficiency. SMUD provides performancebased and prescriptive incentives for motors projects. Projects are also eligible for low-interest SMUD financing.

SMUD's collaboration with OIT is just one example in which an energy services organization has combined its resources with OIT's to benefit both customer and service provider. Your company, too, may be better able to help customers save energy and money. To learn more about the OIT resources available to you, visit OIT's BestPractices Web Site at www.oit.doe. gov/bestpractices, or call the OIT Clearinghouse at 800-862-2086. 
Performance

Optimization Tips

The Rules of the Game

By Don Casada, OIT BestPractices Program

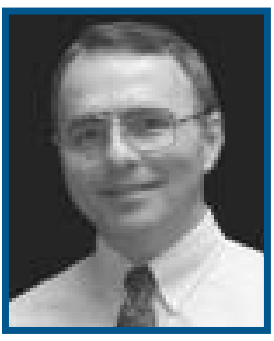

A common impediment to making energy cost-saving changes to systemseven when the change makes sense economically-is securing capital funding approval. In some cases, projects with simple payback periods of less than a year go unfunded because of cash flow constraints, bureaucratic hurdles, competing demands for human and financial resources, and a plethora of other reasons.

But it is an interesting fact that when a piece of equipment breaks and takes a process down, repair funds are almost always available. After all, what's a \$20,000 repair when it's costing $\$ 10,000$ an hour in downtime? Plant operating practices may vary widely, but the availability of maintenance funds in a crisis is a standard. It is, in essence, a rule of the game.

\section{Maintenance: A Defensive Strategy}

In football, the general goal of the defense is to stop the other team's offense as quickly and with as little damage as possible, and get their own team's offense back on the field to try to score points. A critical element of defense is becoming very familiar with the opponent's offense. When the defense recognizes weaknesses and tendencies in the offense, they can employ defensive schemes that are likely to create turnovers, thereby establishing good field position for their offense, and occasionally scoring themselves.

Maintenance work is like playing defense-repair the problem as quickly as possible and get production (the offense) back on line to make money (score points). But if weaknesses in the offense (production) are recognized ahead of time preparations can be made. Then when the defense (maintenance) is called in to play, they can not only get the offense back on the field, but might also score points (reduce operational costs) themselves. Let's call it a maintenance contingency modification (MC mod) scheme.

\section{Strategy in Action}

Let's assume we have a 100-hp vertical turbine pump with six stages. Our review of the application indicates that the pump develops $40 \%$ more head than is currently required. The excess capability is due, in part, to an overly conservative original design, but is also the result of process requirements that have changed with time. This $40 \%$ excess head directly translates into $40 \%$ excess energy cost.

We find a pump that is better suited to the current needs. Estimating purchase and installation costs to be $\$ 20,000$, a 2 -year payback period is calculated (8000 hrs/yr operation at $\$ .04 / \mathrm{kWh}$ ). Although this meets the general criterion for energy-reduction funding at our plant, a cash flow crunch has halted funding of projects such as this one.

But 2 months later, the pump shaft seizes, requiring pump removal to make the repair. One of the pump mechanics recalls the suggested change discussions, and makes an alternate proposal. He suggests removal of two stages (providing a $33 \%$ reduction in head and energy) during the repair, noting that the additional time required to make the modification will be, at most, a couple of hours, at an additional repair cost of about $\$ 200$. (The entire repair cost is $\$ 3,000$.)

\section{Analysis of the Strategy}

In a situation like the one above, the additional cost and risk are so small that even in a cash flow crunch, the decision wouldn't be difficult. But there are other points that are important to draw.

1. Removing two stages doesn't achieve all the potential savings that would come from an entirely new pump. An additional $7 \%$ reduction in energy would still be possible. But more than $80 \%(33 / 40)$ of the potential savings are achieved, and at a trivial cost.
2. The return on investment will frequently be greater (the payback period reduced) in MC mods than in the "ideal" fix (in this case, a different pump). In this example, the \$200 incremental cost is recovered in 8 days through energy savings.

3. If the failure were severe enough to require pump replacement instead of a repair, a more optimal design might cost less than an in-kind replacement. Even if the new pump costs more, the payback period for energy savings is no longer calculated on the total purchase and installation cost of the optimal pump_it is now the differential cost between the optimal and an in-kind replacement. What was a 10 -year payback period might now be 3 months.

4. It is important to include maintenance personnel in discussions of energy-saving opportunities for a variety of reasons. First of all, equipment that frequently requires maintenance has, generally speaking, a higher probability of being an energy waster than equipment that seldom requires repair. Second, if maintenance is aware of a potential energy-saving opportunity, they may come up with a creative alternative, as in this example.

\section{Develop a Maintenance Game Plan}

The maintenance organization can be viewed as a preserver of the status quo, charged with playing defense only. But just as the rules allow defense to score in football, maintenance staff can not only keep production on line, they can also score points during production in industrial settings.

If the game plan includes preparation for contingencies, a maintenance problem can be-as when a football team's offense is forced to punt and the kick coverage forces a fumble-a blessing in disguise.

E-mail Don Casada at doncasada@icx.net. 


\section{Ask the}

\section{Clearinghouse}

This column regularly highlights key questions from industrial customers. The questions are answered by the Office of Industrial Technologies (OIT) Clearinghouse. Through the OIT Clearinghouse, you can access the full portfolio of OIT resources to help make your industry more energy efficient, productive, and competitive. The Clearinghouse can help you find resources, such as publications and software, or information about working with OIT and cost-sharing opportunities. You can call the Clearinghouse for technical advice on a variety of topics, such as motor, steam, compressed air, and process heating systems.

Clearinghouse engineers and technical staff expertly answer a wide range of industrial efficiency questions, 11 hours a day, Monday-Friday. The Clearinghouse also has access to industry experts around the country. Call the OIT Clearinghouse at 800-862-2086, or go to www.oit.doe.gov/ clearinghouse/ for additional information.

Q:

I've heard that steam usually costs about \$3 per thousand pounds. Is this rule-of-thumb still true?

- It's important to understand what is

specifically meant by "the cost of steam." The total cost of steam production includes costs for fuel, operating personnel, maintenance, water treatment, insurance, equipment replacement, and payments on power plant debt service. The effective cost of steam is the cost of steam delivered to a process. The total cost of steam is increased due to consideration of losses between the powerhouse and the point of use. The fuelrelated cost of producing steam considers fuel purchases divided by the quantity of steam produced. This is most likely the cost referenced in the rule-of-thumb you mentioned, and so only this cost component will be considered in this response.

Rules-of-thumb are often long remembered, but we should not trust them during times of price volatility. Prices for all fuels vary. An examination of price trends from Natural Gas Week indicates that prices for natural gas delivered to utilities for most parts of the country were between $\$ 7.50$ and $\$ 9$ per MMBtu (million Btu) as of midDecember. The exceptions are New England/New York (more than \$11/MMBtu) and west coast states (about \$30/MMBtu), which doubled in just one week. Delivered-to-utility natural gas prices are close to those available to large industries with short-term contracts; those with long-term contracts could be less.

The fuel cost of steam generation (in $\$ / 1000$ lbs of steam) is dependent upon fuel type and composition, unit fuel cost, boiler efficiency, feedwater temperature, and steam pressure. The ASME Steam Tables indicate that $1078 \mathrm{Btu}$ are required to produce 1 pound of 150 psig saturated steam-given the availability of $150^{\circ} \mathrm{F}$ feedwater. Assuming a natural gas price of $\$ 8 /$ MMBtu and a boiler efficiency of $81 \%$, the cost of raising steam is:

\section{Steam Cost $=\$ 8 /$ MMBtu $\times 1000$ lbs $\mathrm{x}$ \\ $1078 \mathrm{Btu} / \mathrm{lb} \times 100 / 81$ \\ $=\$ 10.64 / 1000 \mathrm{lbs}$}

The bad news is that the fuel component of the total steam production cost has dramatically increased. The good news is that many steam system conservation measures are now cost-effective. Steam plant performance tests and energy audits conducted under the Enbridge Consumers Gas Company's "Steam Saver" Program show that fuel bills can be reduced by more than $14 \%$ at the average boiler plant, providing an average payback of 2.4 years for dollars spent on conservation improvements. This report was previously featured on Energy Matters Extra. Access the report at: www.oit.doe. gov/bestpractices/explore_library/ emextra/pdfs/enbridge.pdf.

Initiate your steam system improvement program by visiting OIT's BestPractices Steam page at www.oit.doe.gov/bestpractices/ steam. From this Web page, you can download steam tip sheets, case studies, technical references, and financial tools. Take a look at the steam tip sheet Benchmark the Cost of Steam Generation for more on calculating steam costs. It is available on the Web page or from the OIT Clearinghouse.
Guest Column

continued from page 3

$5 \mathrm{~min} / \mathrm{hr} \times 8 \mathrm{hrs} /$ day $\div 60 \mathrm{~min} / \mathrm{hr}$ $=0.67 \mathrm{hr} /$ day

$0.67 \mathrm{hr} /$ day x 260 working days/yr $=174 \mathrm{hrs} / \mathrm{yr}$

$174 \mathrm{hrs} / \mathrm{yr}$ x \$30/hr/employee x 50 employees

$=\$ 261,000 / \mathrm{yr}$

Long Equipment Life

Effective maintenance programs are key to maximizing the useful life of significant equipment assets. A CMMS is ideal for helping achieve this result.

Consider a facility that has a 5-year-old centrifugal chiller with an original 20-year expected useful life. Poor maintenance reduces this to only 15 years. With improved maintenance, the chiller's expected useful life can be extended to 18 years. The longterm savings would be more than $\$ 120,000$ using this calculation:

Annual inflation rate (estimated) $=2 \%$ Internal cost of capital $=8.5 \%$ Replacement value today $=\$ 500,000$ Replacement value in 10 years $=\$ 609,500$ Replacement value in 13 years $=\$ 646,800$ Increase over 3 years $=\$ 37,300$

Future value of $\$ 609,500$ after 3 years $=\$ 767,800$

Savings from delaying the purchase by 3 years

$=\$ 767,800-\$ 609,500-\$ 37,300$

$=\$ 121,000$

The CMMS will direct equipment maintenance activities along the manufacturer's recommended guidelines. In combination, these are all designed to extend the life of the equipment.

\section{Numbers Win with the CFO}

These are very powerful and conservative examples of the possibilities. Use these numbers to demonstrate that implementing a CMMS is not simply an expenditure, but an investment with significant returns. These are the numbers that win with the CFO.

Chris Christy is the senior mechanical consultant with LawGibb Asset Reliability Management Services, in Atlanta, GA. He focuses on developing and applying information technology solutions to facility engineering management functions. Contact him by phone at 770-360-0591 or e-mail: CCHRISTY@kennesaw.Lawco.com. 


\section{New Steam System Scoping Tool Provides Assessment Information}

A Steam System Scoping Tool is now available, free of charge, for use by steam system energy managers and operations personnel. The purpose of the Scoping Tool-developed by OIT's BestPractices program and the BestPractices Steam Technical Subcommittee-is to assist industrial steam users to:

- Evaluate their steam system operations against identified best practices

- Develop a greater awareness of opportunities available for improving steam system energy efficiency and productivity

- Compare their Scoping Tool self-evaluation results with those obtained by others

\section{Assess Your Steam System}

This version of the Steam System Scoping Tool, version $1.0 \mathrm{c}$, is in a Microsoft Excel spreadsheet format and includes seven worksheets:

1. Introduction

2. Steam System Basic Data

3. Steam System Profiling

4. Steam System Operating PracticesTotal Steam System

5. Steam System Operating PracticesBoiler Plant

6. Steam System Operating PracticesDistribution, End Use, Recovery

7. Summary Results

The Scoping Tool can be completed by answering the questions in Worksheets 2 through 6 . When you complete Worksheet 2 , you provide profiling information for your steam system. Answering the questions in Worksheets 3 through 6 permits you to perform the self-evaluation of your steam system. When you have completed all of the questions in Worksheets 3 through 6, you can see a summary of your Scoping Tool results in Worksheet 7 .

\section{Submit Results to BestPractices}

In addition to using Scoping Tool results to identify opportunities to improve steam system operations, steam users are encouraged to provide their Scoping Tool results to BestPractices Steam. A database of steam user responses to the Scoping Tool questions, and summary information from this database will be made available on the BestPractices Steam Web page or directly to anyone who requests it. All Scoping Tool results collected from steam users will be held in strict confidence.

Six of OIT's Industrial Assessment Centers are helping to evaluate the Scoping Tool. These university-based centers enlist engineering students and faculty to conduct energy audits or industrial assessments and provide recommendations to small and medium-size manufacturers. The six universities participating in this project will each be performing three 1-day steam system assessments at industrial plants; they will utilize and test the Scoping Tool as part of their assessment efforts.

\section{Order the Scoping Tool}

You can obtain version $1.0 \mathrm{c}$ of the Steam System Scoping Tool by contacting the OIT Clearinghouse by phone at 800 862-2086 or e-mail: steamline@energy. wsu.edu. Or contact:

Dr. Anthony Wright

Oak Ridge National Laboratory

National Transportation Research Center

2360 Cherahala Boulevard, Room K01

Knoxville, TN 37932

E-mail:wrightal@ornl.gov

Phone: 865-946-1353

\section{We Stand Corrected}

Energy Matters has learned of two misprints in the November/December issue, and we sincerely apologize for the errors. In the page 2 feature about AMCAST's successful plant-wide assessment, the University of Dayton and Ohio's State Energy Office should have been identified as two separate entities. The Ohio Department of Development's Office of Energy Efficiency, in Columbus, Ohio, is the "State Energy Office" that helped facilitate the AMCAST project.

On page 4, in Emissivity: the Unknown Factor, the denominator in the second equation was printed incorrectly. Limited space prevents us from reprinting the equation here; however, the corrected version of the article is available online at Energy Matters Extra: www.oit.doe.gov/ bestpractices/explore_library/emextra.
Letters to the Editor

Energy Matters welcomes your typewritten letters and e-mails. Please include your full name, address, organization, and phone number, and limit comments to 200 words. Address correspondence to:

Michelle Mallory, Letters to the Editor

NREL, MS 1713

1617 Cole Blvd.

Golden, CO 80401

E-mail:michelle_sosa-mallory@nrel.gov

We publish letters of interest to our readers on related topics, comments, or criticisms/corrections of a technical nature. Preference is given to letters relating to articles that appeared in the previous two issues. Letters may be edited for clarity, length, and style.

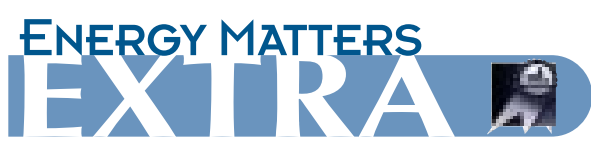

For more on the maintenance-related topics featured in this issue, visit Energy Matters Extra. Read about Thomaston Textile Mill's implementation of compressed air system improvements that have reduced compressor downtime, lowered maintenance costs, saved more than $\$ 100,000$ in energy costs, and improved product quality. Also find articles on the role of predictive maintenance and the $A B C s$ of maintenance budgets.

On the topic of computerized maintenance management systems (CMMS), we've included a feature to help you with decision-making about installing such a system. (Be sure to read this issue's Guest Column on page 3 , which focuses on CMMS.)

Get information on OIT solicitations in the areas of Aluminum and Metalcastingthese could be cost-shared R\&D opportunities for your company. See what's new on the BestPractices Web site, and check out upcoming BestPractices training and workshops.

All this is available online at Energy Matters Extra: www.oit.doe.gov/bestpractices/ explore_library/emextra. 


\section{Coming Events}

\section{OIT Expo 4-Global Competition: Challenges and Solutions}

OIT's 4th Industrial Energy Efficiency Symposium and Exposition, "Global Competition: Challenges and Solutions," is February 19-22, 2001, in Washington, DC. Plan to attend this national conference to find out what challenges face the most energy-intensive industries and to learn about new technological and marketing opportunities to address these challenges. To find out more about the conference, visit the the Web site at www.oitexpo4.com, or call 877-648-7967.

\section{Improving Productivity Through BestPractices}

- March 28, 2001, in Atlantic City, NJ

For more information please call Spirax Sarco, Inc. at 800-251-7676.

- April 2001 (date TBD), in Washington, DC

For more information, please call the Alliance to Save Energy at 202-530-2225.

\section{GlobalCon Energy and facility Management and Expo}

- March 29-30, 2001, in Atlantic City, NJ

For more information, please call the Association of Energy Engineers (AEE) at 770-279-4390.

\section{Industrial Energy TeChnology Conference}

- May 1-3, 2001 Houston, TX

For more information, please call Texas A\&M University at 409-845-1508.

\section{ACEEE SUMMER STUdY ON ENERGY EFfICIENCY IN INDUSTRY}

- July 24-27, 2001, in Tarrytown, NY

For more information, please call the American Council for an Energy-Efficient Economy (ACEEE) at 202-429-8873.

\section{Capturing the Value of Steam Efficiency}

Dates TBD for workshops in:

- Reading, PA - Chicago, IL Mobile, AL a Los Angeles, CA

For information, please call the OIT Clearinghouse at 800-862-2086.

To keep up-to-date on OIT training and other events, check the calendar regularly on Energy Matters Extra at www.oit.doe.gov/bestpractices/explore_library/emextra.

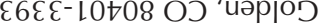
рцеләрпя әоОว $\angle L 9 L$

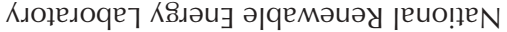

\section{BestPractices}

The Office of Industrial Technologies (OIT) BestPractices initiative and its Energy Matters newsletter introduces industrial end users to emerging technologies and wellproven, cost-saving opportunities in motor, steam, compressed air, and other plantwide systems. For overview information and to keep current on what is happening office wide, check out the newsletter-The OIT Times-at www.oit.doe.gov/oit-times.

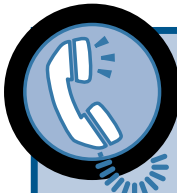

INFORMATION Clearinghouse

Do you have questions about using energy-efficient process and utility systems in your industrial facility? Call the OIT Information Clearinghouse for answers, Monday through Friday 9:00 a.m. to 8:00 p.m. (EST).

HOTLINE: 800-862-2086

Fax: 360-586-8303, or access our homepage at www.oit.doe.gov/ clearinghouse.

\section{DOE Regional Support Office} Representatives

- Tim Eastling, Atlanta, GA, 404-347-7141

- Scott Hutchins, Boston, MA, 617-565-9765

- Brian Olsen, Chicago, IL, 312-886-8579

- Gibson Asuquo, Denver, CO, 303-275-4841

- Julia Oliver, Seattle, WA, 510-637-1952

- Maryanne Daniel, Philadelphia, PA, 215-656-6964

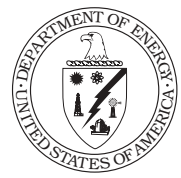

This document was produced for the Office of Energy Efficiency and Renewable Energy at the U.S. Department of Energy (DOE) by the National Renewable Energy Laboratory, a DOE national laboratory.

DOE/GO-102000-1183 • January/February 2001

Printed with a renewable-source ink on paper containing at least $50 \%$ wastepaper, including $20 \%$ postconsumer waste 